\title{
Potential problems of removing one invasive species at a time: a meta-analysis of the interactions between invasive vertebrates and unexpected effects of removal programs
}

Sebastián A Ballari, Sara E Kuebbing, Martin A Nuñez

Although the co-occurrence of nonnative vertebrates is a ubiquitous global phenomenon, the study of interactions between invaders is poorly represented in the literature. Limited understanding of the interactions between co-occurring vertebrates can be problematic for predicting how the removal of only one invasive-a common management scenario-will affect native communities. We suggest a trophic food web framework for predicting the effects of single-species management on native biodiversity. We used a literature search and meta-analysis to assess current understanding of how the removal of one invasive vertebrate affects native biodiversity relative to when two invasives are present. The majority of studies focused on the removal of carnivores, mainly within aquatic systems, which highlights a critical knowledge gap in our understanding of co-occurring invasive vertebrates. We found that removal of one invasive vertebrate caused a significant negative effect on native species compared to when two invasive vertebrates were present. These unexpected results could arise because of the positioning and hierarchy of the co-occurring invasives in food web (e.g. carnivore-carnivore or carnivore-herbivore). We consider that there are important knowledge gaps to determinate the effects of multiple co-existing invaders on native ecosystems, and this information could be precious for management. 
1 Potential problems of removing one invasive species at a time: a meta-analysis of the

2

\section{Abstract}

5

\section{Keywords}

\author{
Ballari SA, Kuebbing SE, Nuñez MA
}

Although the co-occurrence of nonnative vertebrates is a ubiquitous global phenomenon, the study of interactions between invaders is poorly represented in the literature. Limited understanding of the interactions between co-occurring vertebrates can be problematic for predicting how the removal of only one invasive - a common management scenario-will affect native communities. We suggest a trophic food web framework for predicting the effects of single-species management on native biodiversity. We used a literature search and meta-analysis to assess current understanding of how the removal of one invasive vertebrate affects native biodiversity relative to when two invasives are present. The majority of studies focused on the removal of carnivores, mainly within aquatic systems, which highlights a critical knowledge gap in our understanding of co-occurring invasive vertebrates. We found that removal of one invasive vertebrate caused a significant negative effect on native species compared to when two invasive vertebrates were present. These unexpected results could arise because of the positioning and hierarchy of the co-occurring invasives in food web (e.g. carnivore-carnivore or carnivore-herbivore). We consider that there are important knowledge gaps to determinate the effects of multiple co-existing invaders on native ecosystems, and this information could be precious for management.

animals, carnivores, co-occurrence, invasional meltdown, meta-analysis, nonnative 


\section{INTRODUCTION}

Invasive vertebrates can alter native communities and ecosystems through many pathways including predation, competition, reducing food web complexity, hybridization, competitive exclusion, and increasing the risk of extinction of native species (White et al., 2008; Doherty et al., 2015, Houde et al. 2015). Many ecosystems now host numerous invasive species that directly or indirectly interact with one another and impact native species populations and ecosystem processes (Courchamp et al., 2011; Porter-Whitaker et al., 2012; Meza-Lopez \& Siemann, 2015). Interactions between these co-occurring invaders are of superlative interest for wildlife management because managers can often only control or eradicate a single invasive species at a time (Glen et al., 2013). Without prior knowledge of invader interactions, removal of only a single invader can lead to an increase in the population size of other invasives or a decrease in the population size of native species (Zavaleta et al., 2001; Campbell et al., 2011; Ruscoe et al., 2011).

Predicting the community-level consequences of management of a single invasive species requires an understanding of both the interactions between co-occurring invaders and their combined impacts (van Zwol et al., 2012; Latorre et al., 2013). In an initial review of 45 invasive animal interaction studies, Jackson (2015) showed that the combined ecological impacts of multiple invaders were additive, but the mean effect size was non-additive and lower than predicted. This analysis included many animal taxonomic groups (with no mammalian cases) and $\sim 96 \%$ the reported interactions were from aquatic environments. In our study, we focus on invasive vertebrates because it is a homogeneous group to compare and includes some of the 
46

47

48

most damaging and widespread invasive species that are frequent targets for management (White et al., 2008; Dawson et al., 2015).

Interactions between nonnative species can be positive, negative, or neutral (Kuebbing \& Nuñez, 2015; Jackson, 2015; Doherty et al., 2015). Most research on invasive species interactions has focused on facilitative interactions (i.e., invasional meltdown hypothesis, Simberloff \& Von Holle, 1999; Simberloff, 2006), the replacement of one invasive by another invasive (Lohrer \& Whitlatch, 2002), or mechanics that involve negative interactions, such predation (e.g. hyperpredation) and competence (e.g. mesopredator release, Blanco-Aguiar et al., 2012; Doherty et al., 2015; Ringler et al., 2016).

Many ecosystems host numerous species with different trophic positions that make up a complex network interactions (Fig. 1a; Zavaleta et al. 2001). It may be possible to predict these type of interactions between vertebrate invaders and their potential impacts because the interactions among multiple invasive species should vary depending on the traits, trophic positions, and interactions of the co-occurring invasive and native species in the community (Fig 1a; Zavaleta et al., 2001; Roemer et al., 2002; Didham et al., 2009; Oyugi et al., 2012). For example, two invasive carnivores occupying the same trophic position may predate on similar native species or utilize similar habitats, which could lead to both invaders investing energy to compete against one another(Fig. 1b; Griffen et al., 2008). Thus, the removal of only one invasive predator could release the population of the second invasive predator (i.e. mesopredator release), which could ultimately cause a greater impact on the native prey species (Courchamp, 1999). We may also expect different outcomes of single-species management when multiple coexisting invasive species occupy different positions in food webs (Fig. 1c, 1d; Zavaleta et al., 2001). In a hypothetical coexistence scenario of an invasive carnivore predator and an invasive 
69 herbivore, we might expect that the removal of the invasive carnivore could reduce predation

70 pressure on the invasive herbivore prey and allow its population to increase (Fig. 1c; Bergstrom

71 et al., 2009). The consequence of this herbivore release may indirectly affect native herbivores

72 through competition, or directly threaten a native plant through herbivory (Fig. 1c, Vázquez

73 2002). On the other hand, if the removed species is an invasive herbivore prey, the invasive

74 carnivore predator would be forced to change their diet and search for native prey (i.e.

75 hyperpredation, Fig. 1d; Bate \& Hilker, 2012). These hypothetical examples illustrate how the

coexistence of invasive vertebrates and subsequent removal of one of them can lead to

predictable impacts on native biodiversity (Zavaleta et al. 2001).

We assessed whether the trophic positions of invasive vertebrates could predict the consequences of removal of only a single invasive species on native species. To do this, we conducted an extensive literature search of studies that evaluated the impact of removing a single invasive vertebrate while leaving a second invasive present on native biodiversity. We focused on invasive vertebrates owing to their biological and socioeconomic importance and because there are still many gaps of information on management of invasive vertebrates. We ask (1) what is the combined effect of two invasive vertebrate species on native biodiversity relative to a single invasive vertebrate?; (2) does the removal of a single invasive vertebrate reduce the impact on native species?; and finally (3) what traits of invasive vertebrate species (e.g. trophic position) predict these interactions?

\section{MATERIALS \& METHODS}

We searched for peer-reviewed literature on invasive vertebrate interactions (Fig. 2) using the database Web of Science ${ }^{\circledR}$ and the methodology proposed by Kuebbing \& Nuñez (2015). We 
92 used the keywords "species" AND "invas*" OR "alien" OR "nonnative" OR "non-indigenous",

93 and also used as search terms the genres of mammals, birds, reptiles, amphibians and fish

94 described in the list of 100 most damaging invasive species in Global Invasive Species Database

95 (http://www.issg.org/database/species/) and categories filter (Supporting Information 1). From

96 the articles returned by this search ( $n=403$, Fig. 2$)$, we selected those that met the following

97 criteria: (1) studied the impact of an invasive vertebrate on a native species; (2) included a

98 treatment where two invasive vertebrate species were present; and (3) included a treatment

99 where one invasive vertebrate species was removed. This selection restricted our meta-analysis

100 to eight published studies that comprised 128 individual observations (Table 1). Finally, to

101 investigate if there were any species or habitat characteristics that affected the type of interaction

102 we collected the following factors for each observation: (1) trophic position (e.g., carnivore,

103 herbivore, omnivore) of each native and invasive species; and (2) if the invasive species

104 overlapped in their native ranges (Supporting Information 3, Sup. Inf. 4). We recorded the

105 following descriptive variables (1) invasive species studied; (2) native species studied; (3)

106 location of study; (4) habitat type (forest, wetland, freshwater, garrigue).We estimated mean

107 effect sizes using Hedges' $d+$, which measures the difference between treatment groups (i.e.,

108 performance of a native species in the presence of one invasive species, see Supporting

109 Information 4) and control groups(i.e., performance of a native species in the presence of two

110 invasive species, see Supporting Information 4).This method corrects for small sample size bias

111 and avoids overestimating effect sizes when study sample size is low (Gurevitch \& Hedges,

112 2001; Lajeunesse \& Forbes, 2003). When necessary, we extracted data with extraction software

113 (ImageJ 1.449p ${ }^{\odot} 2015$ Wayne Rasband). We considered all response variables in each study

114 (e.g., if a study measured fitness and growth of a native animal). We consider a mean effect size 
115 to be significant when its $95 \%$ confidence intervals do not overlap zero. Because of potential

116 publication bias against studies with negative results or studies with higher sample sizes having a

117 probability of finding effects, we assessed potential publication bias by plotting the sample size

118 against the Hedges' $d$ value (e.g., funnel plot analysis, Palmer, 1999). We found a funnel-shape

119 distribution of data that is expected in the absence of publication bias (Supporting Information

120 2).Because all 8 studies reported multiple response variables for the affected native species, there

121 is a potential issue with independence among observations within a study. To avoid this problem,

122 we also ran the meta-analysis on a reduced dataset randomly selecting a single response variable

123 to describe the effect of the removal of a specific nonnative species on a specific native species.

124 The mean effect sizes for the reduced dataset was similar to the mean effect size for the entire

125 dataset, and the 95\% confidence intervals overlapped for both datasets (Table 2 and Supporting

126 Information 5). Therefore, we felt confident including all 128 observations in our analysis.

128 3. RESULTS

129 We found that the removal of a single invasive species always led to a negative or neutral mean 130 effect on native species performance or survival (Fig. 3; Table 2). Surprisingly, we never found a 131 positive effect size where the removal of one invasive led to an increase in native performance

132 (Table 2). Related to trophic position, we found that the majority of the invasive vertebrates 133 studied were strict carnivores $(52.9 \%, \mathrm{n}=9)$, while the minority were herbivores $(23.5 \%, \mathrm{n}=4)$ or 134 omnivores $(23.5 \%, n=4$; Supporting Information 3). Likewise, the vast majority of observations 135 included interactions between two carnivorous species $(82.8 \%, n=106)$, while only 11

136 observations included interactions between an invasive herbivore and omnivore (8.6\%) and a 137 single observation between two omnivores. Of the 17 species reviewed, there were 8 fish, 6 
138 mammals, 2 amphibians and 1 marsupial (Supporting Information 3). Regarding the location, the

139 majority of the observations were from North America (Canada and United States, 82.8\%,

$140 \mathrm{n}=106$ ), while only $12.5 \%$ were in Oceania (New Zealand, $\mathrm{n}=16$ ) and $4.7 \%$ in Europe (United

141 Kingdom and Spain, $n=6)$. Only 14.8\% $(n=19)$ of the observations were on islands. Finally we

142 found significantly negative mean effect sizes regardless of the whether the nonnative species

143 overlapped in their native range, and across habitat types (Table 2).

144

\section{DISCUSSION}

Our results show that the removal of a single invasive species led to a negative or neutral mean effect on native species performance or survival. This could suggest, in accordance with Jackson (2015), that the interactions between vertebrate invaders are antagonistic and reduce the population size and impact of other invaders. The studies we reviewed overwhelmingly considered the effects of two carnivorous species on native prey species $(82.8 \%, \mathrm{n}=106)$, so we may need to limit this interpretation to this particular scenario. It is likely that in scenarios where the co-occurring invaders are not competing predators (e.g. carnivore-herbivore), the positive effects on native biodiversity could occur at different trophic levels, when carnivore predator are removed (e.g. in native omnivores and plants in Fig. 1b, 1c, Zavaleta et al., 2001; Vázquez, 2002; Griffen et al., 2008). In contrast, in this scenario, the removal of predator also could lead to mesopredator release (native or nonnative) to the detriment of native species (Zavaleta et al., 2001). On other hand, when invasive herbivore is removed, plants (native -Fig.1b- or nonnative) could have significant benefits (Courchamp et al. 2003). vertebrate species on native biodiversity, which highlights research areas in need of further 
161 study. The major knowledge gap is expanding our understanding of removal of herbivore and

162 omnivore vertebrate invaders may influence other nonnative and native species in the food web.

163 The majority of the invasive vertebrates we studied were strict carnivores and the minority were

164 herbivores or omnivores. Likewise, most of the observations included interactions between two

165 carnivorous species, while few recorded interactions between an invasive herbivore and

166 omnivore or two omnivores. Globally, there are many examples of co-occurrence of invasive

167 vertebrates that occupy these missing trophic positions (herbivorous "h" - omnivorous "o" (e.g.

168 livestock-wild boar, Desbiez et al., 2009) or their combinations "h"-"h"(e.g. cattle-deer, Flueck et

169 al. 1999) or "o"-"o"(e.g. brushtail possum-black rat, Wilson et al., 2006). For example, in South

170 America and New Zealand, large nonnative herbivores such as cattle, goat, and deer modify and

171 alter plant communities, which affect other invasive herbivore species such as rabbits and hares,

172 and/or omnivores like wild boar, rats, and opossums (Glen et al., 2013; Lantschner et al., 2013;

173 Whitehead et al., 2014). However, we did not find studies that evaluated the consequences or the

174 individual effects of single-invader eradication of these invasive species combinations. Also, the

175 studies we found lacked information on vertebrate groups like reptiles and birds. However, in

176 different regions of the world, several species of invasive reptiles (e.g. Python bivittatus,

177 Varanus niloticus, Iguana iguana, in USA, Engeman et al., 2011) or invasive birds (e.g.

178 Psittacula krameri, Acridotheres tristis, Sturnus burmannicus in Israel, Orchan et al., 2013)

179 coexist and affect native biodiversity. Although we did not find that the removal of one invasive

180 led to an increase in native performance, we do not think this is because this does not occur. In

181 nature, there are many possible scenarios where the removal of an invasive species might

182 negatively affect the presence of another invader and positively affect native biodiversity (e.g.,

183 invasive host and pathogens, invasive specialize mutualism). These gaps could contribute more 
184 insight into the implications of single-species invasive removal and potentially expand the results 185 found in this work.

In wildlife management is crucial to understand the outcomes of the applied methods

187

188

189

190

191

192

193

194

195

196

197

198

199

200

201

202

203

204

205

(e.g. Zavaleta et al., 2001), in particular the removal of only a single invasive species in a scenario with multiple invasive species (Bonnaud et al., 2010). But also, it is clear that we need more studies and experiments across different regions, invasive species combinations, interactions with different trophic positions, and management strategies to test if we can predict or anticipate the results of these invasive interactions (Smith, 2005; Bergstrom et al., 2009). Eradications efforts are very complex owing to the fact that they need exceptional planning. Even though eradications may benefit some biological diversity, they can have unwanted and unexpected impacts on native species and ecosystems (Zavaleta et al., 2001; Caut et al. 2009; Ruscoe et al., 2011). We believe that when possible, management initiatives should consider integrated management of invasive species, considering trophic interactions between invaders and native species, to detect possible direct or indirect unexpected consequences for native species and ecosystems (Zavaleta et al., 2001; Caut et al., 2009; Ruscoe et al., 2011; Glen et al., 2013; Ringler et al., 2016).

We suggest that considering the type of interactions and trophic positions of the cooccurring invasive vertebrates might provide a predictive framework for understanding when single-species management will lead to unwanted and unexpected effects, but more data is necessary to test this hypothesis. We call for more studies of the effects of co-occurring invasive vertebrates, particularly of scenarios where invaders occupy the following trophic positions: predator-herbivore; predator-predator; predator-omnivore; omnivore-herbivore, herbivore- 
206 herbivore. These studies will clarify and bring to light possible outcomes of the removal of

207 single-invaders on native biodiversity.

208

\section{Authors' contributions}

210 SAB designed the study, conducted the literature search and data collection, and wrote the first

211 draft of the manuscript; SEK help in the design of the study, the statistical analyses, and provided

212 comments on the manuscript; MAN participated in the design of the study, coordinated the

213 study, and provided comments on the manuscript. All authors gave final approval for

214 publication.

\section{Acknowledgments}

217 The authors thank Mariano Rodriguez Cabal for thoughtful comments on previous versions of 218 this manuscript.

\section{References}

221

222

223

224

225
Bate AM, Hilker FM. 2012. Rabbits protecting birds: hypopredation and limitations of hyperpredation. Journal of theoretical biology 297:103-115.

Bergstrom DM., Lucieer A, Kiefer K, Wasley J, Belbin L, Pedersen TK, Chown SL. 2009. Indirect effects of invasive species removal devastate World Heritage Island. Journal of Applied Ecology 46:73-81. 
226 Bonnaud E, Zarzoso-Lacoste D, Bourgeois K, Ruffino L, Legrand J, Vidal E. 2010. Top-predator

227

228

229

230

231

232

233

234

235

236

237

238

239

240

241

242

243

244

245 control on islands boosts endemic prey but not mesopredator. Animal Conservation $13: 556-567$.

Campbell KJ, Harper G, Algar D, Hanson CC, Keitt BS, Robinson S. 2011. Review of feral cat eradications on islands.In Veitch CR, Clout MN, Towns DR(eds.). Island invasives: eradication and management. IUCN,(International Union for Conservation of Nature), Gland, Switzerland, 37-46.

Caut S, Angulo E, Courchamp F. 2009. Avoiding surprise effects on Surprise Island: alien species control in a multitrophic level perspective. Biological Invasions 11:1689-1703.

Courchamp F, Caut S, Bonnaud E, Bourgeois K, Angulo E, Watari Y. 2011. Eradication of alien invasive species: surprise effects and conservation successes. Island Invasives: Eradication and Management 285-289.

Courchamp F, Langlais M, Sugihara G. 1999. Cats protecting birds: modelling the mesopredator release effect. Journal of Animal Ecology 68: 282-292.

Dawson J, Oppel S, Cuthbert RJ, Holmes N, Bird JP, Butchart SH, Spatz DR, Tershy B. 2015. Prioritizing islands for the eradication of invasive vertebrates in the United Kingdom overseas territories. Conservation Biology 29:143-153.

Desbiez ALJ, Santos SA, Keuroghlian A. 2009. Predation of young palms (Atalea phalterata) by feral pigs in the Brazilian Pantanal. Suiform Soundings 9:35-41. 
246 Didham RK, Barker GM, Costall JA, Denmead LH, Floyd CG, Watts CH. 2009. The interactive

247

248

249

250

251

252

253

254

255

256

257

258

259

260

261

262

263

264

265

266

effects of livestock exclusion and mammalian pest control on the restoration of invertebrate communities in small forest remnants. New Zealand Journal of Zoology 36:135-163.

Doherty TS, Dickman CR, Nimmo DG, Ritchie EG. 2015. Multiple threats, or multiplying the threats? Interactions between invasive predators and other ecological disturbances. Biological Conservation 190:60-68.

Engeman R, Jacobson E, Avery ML, Meshaka Jr WE. 2011. The aggressive invasion of exotic reptiles in Florida with a focus on prominent species: A review. Current Zoology 57:599612.

Glen AS, Atkinson R, Campbell KJ, Hagen E, Holmes ND, Keitt BS, Parkes JP, Saunders A, Sawyer J, Torres H. 2013. Eradicating multiple invasive species on inhabited islands: the next big step in island restoration?. Biological Invasions 15:2589-2603.

Global Invasive Database. Available at http://www.issg.org/database/species/ (accessed12 December 2015).

Griffen BD, Guy T, Buck J.C. 2008. Inhibition between invasives: a newly introduced predator moderates the impacts of a previously established invasive predator. Journal of Animal Ecology 77:32-40.

Gurevitch J, Hedges LV. 2001. Meta-analysis: combining the results of independent experiments. Pages 347-369 in Scheiner SM, Gurevitch J (eds). Design and analysis of ecological experiments. Oxford University Press, New York, New York, USA. 
267 Houde ALS, Wilson CC, Neff BD. 2015. Competitive interactions among multiple non-native salmonids and two populations of Atlantic salmon. Ecology of Freshwater Fish 24:44-55.

269 Jackson MC. 2015. Interactions among multiple invasive animals. Ecology 96:2035-2041.

270 Kuebbing SE, Nuñez MA. 2015. Negative, neutral, and positive interactions among nonnative plants: patterns, processes, and management implications. Global Change Biology 21:926-934.

273

274
Lantschner MV, Rusch V, Hayes JP. 2013. Do exotic pine plantations favour the spread of invasive herbivorous mammals in Patagonia?.Austral Ecology 38:338-345.

Lajeunesse MJ, Forbes MR. 2003.Variable reporting and quantitative reviews: a comparison of three meta-analytical techniques. Ecology Letters 6:448-454.

Latorre L, Larrinaga AR, Santamaría L. 2013. Combined impact of multiple exotic herbivores on different life stages of an endangered plant endemism, Medicago citrina. Journal of Ecology 101:107-117.

Lohrer AM, Whitlatch RB. 2002. Interactions among aliens: apparent replacement of one exotic species by another. Ecology 83:719-732.

Orchan Y, Chiron F, Shwartz A, Kark S. 2013. The complex interaction network among multiple invasive bird species in a cavity-nesting community. Biological Invasions 15:429-445.

Oyugi DO, Cucherousset J, Britton JR. 2012. Temperature-dependent feeding interactions between two invasive fishes competing through interference and exploitation. Reviews in Fish Biology and Fisheries 22:499-508. 
287 Porter-Whitaker AE, Rehage JS, Liston SE, Loftus WF. 2012. Multiple predator effects and

288

289

290

291

292

293

294

295

296

297

298

299

300

301

302

303

304

305

306 native prey responses to two non-native Everglades cichlids. Ecology of Freshwater Fish $21: 375-385$.

Rayner MJ, Hauber ME, Imber MJ, Stamp RK, Clout MN. 2007. Spatial heterogeneity of mesopredator release within an oceanic island system. Proceedings of the National Academy of Sciences 104:20862-20865.

Ringler D, Russell JC, Le Corre M. 2015. Trophic roles of black rats and seabird impacts on tropical islands: Mesopredator release or hyperpredation?. Biological Conservation 185:75-84.

Roemer GW, Donlan CJ, Courchamp F. 2002. Golden eagles, feral pigs, and insular carnivores: how exotic species turn native predators into prey. Proceedings of the National Academy of Sciences 99:791-796.

Ruscoe WA, Ramsey DS, Pech RP, Sweetapple PJ, Yockney I, Barron MC, Perry M, Nugent G, Carran R, Warne R, Brausch C, Duncan RP. 2011. Unexpected consequences of control: competitive vs. predator release in a four-species assemblage of invasive mammals. Ecology Letters 14:1035-1042.

Simberloff D. 2006. Invasional meltdown 6 years later: important phenomenon, unfortunate metaphor, or both?. Ecology Letters 9:912-919.

Simberloff D, Von Holle B. 1999. Positive interactions of nonindigenous species: invasional meltdown? Biological invasions 1:21-32. 
307 Smith KG. 2005. Effects of nonindigenous tadpoles on native tadpoles in Florida: evidence of 308 competition. Biological Conservation 123:433-441.

309 Van Zwol JA, Neff BD, Wilson CC. 2012. The effect of nonnative salmonids on social

310 dominance and growth of juvenile Atlantic salmon. Transactions of the American

$311 \quad$ Fisheries Society 141:907-918.

312 Vázquez DP. 2002. Multiple effects of introduced mammalian herbivores in a temperate forest. Biological invasions 4:175-191.

314 White PC, Ford AE, Clout MN, Engeman RM, Roy S, Saunders G. 2008. Alien invasive 315 vertebrates in ecosystems: pattern, process and the social dimension. Wildlife Research $316 \quad 35: 171-179$.

317 Whitehead AL, Byrom AE, Clayton RI, Pech RP. 2014. Removal of livestock alters native plant 318 and invasive mammal communities in a dry grassland-shrublands ecosystem. Biological Invasions 16:1105-1118.

Wilson DJ, Ruscoe WA, Burrows LE, McElrea LM, Choquenot D. 2006. An experimental study of the impacts of understorey forest vegetation and herbivory by red deer and rodents on seedling establishment and species composition in Waitutu Forest, New Zealand. New Zealand Journal of Ecology 30:191-207. ecosystem context. Trends in Ecology \& Evolution 16:454-459. 


\section{Figure 1 (on next page)}

Hypothetical food interaction webs with co-occurring native and invasive species

Fig 1 - Hypothetical food interaction webs with co-occurring native and invasive species adapted from Zavaleta et al. 2001. The trophic level of co-occurring invaders could influence outcomes when a single invasive species is removed (red cross; b, c, d). In "a" hypothetical food web based in interaction of carnivore top predators, omnivores, herbivore preys and plants. In "b" the removal of a carnivore releases nonnative herbivores, and native omnivores and predators. In " $\mathrm{C}$ " the removal of a nonnative herbivore reduces population size of the competing native herbivore. In " $d$ " the removal of only one invasive carnivore releases the other invasive carnivore predating on native herbivores and native omnivores reducing their populations. Thicker lines represent larger population sizes 
(a)

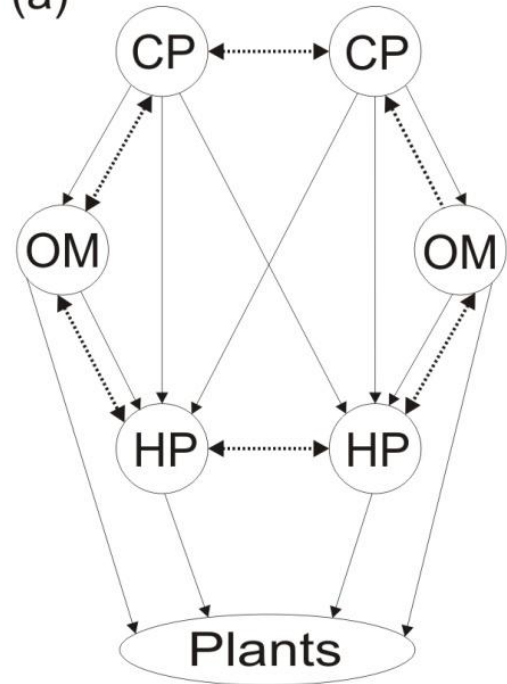

(c)

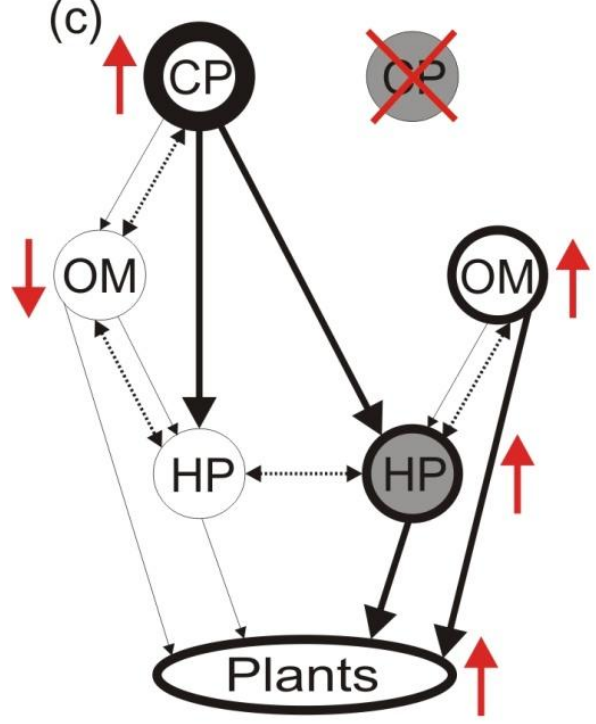

(b)

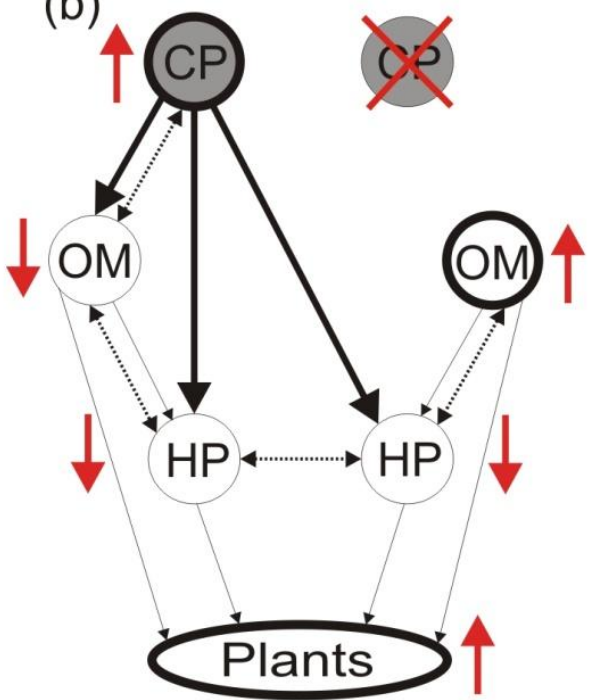

(d)
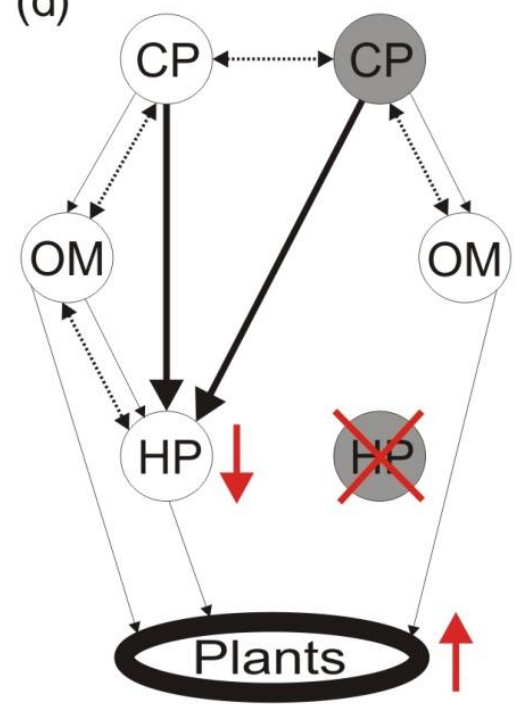

Native species

Invasive species

CP: Top carnivore predator

OM: Omnivore

HP: Herbivore prey $\longrightarrow$ Predation

$\leftrightarrow \cdots \cdots$ Competition

$\uparrow$ Population growth

$\downarrow$ Population decline 


\section{Figure 2 (on next page)}

Flow diagram

Fig 2 - A flow diagram of the screening protocol for paper selection in this study (from Moher D, Liberati A, Tetzlaff J, Altman DG, The PRISMA Group (2009). Preferred Reporting Items for Systematic Reviews and Meta-Analyses: The PRISMA Statement. PLoS Med 6(6): e1000097. doi:10.1371/journal.pmed1000097) 

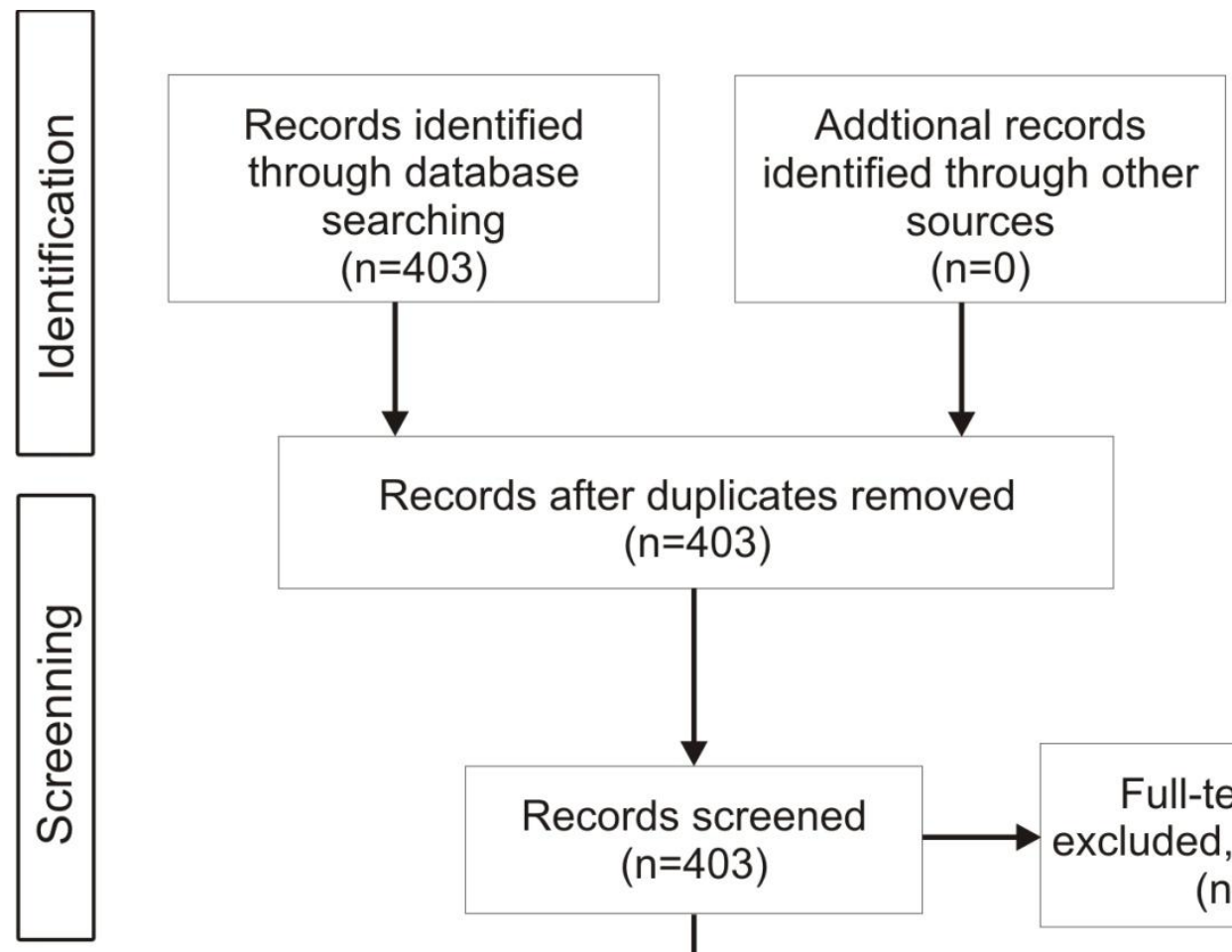

Records after duplicates removed $(n=403)$
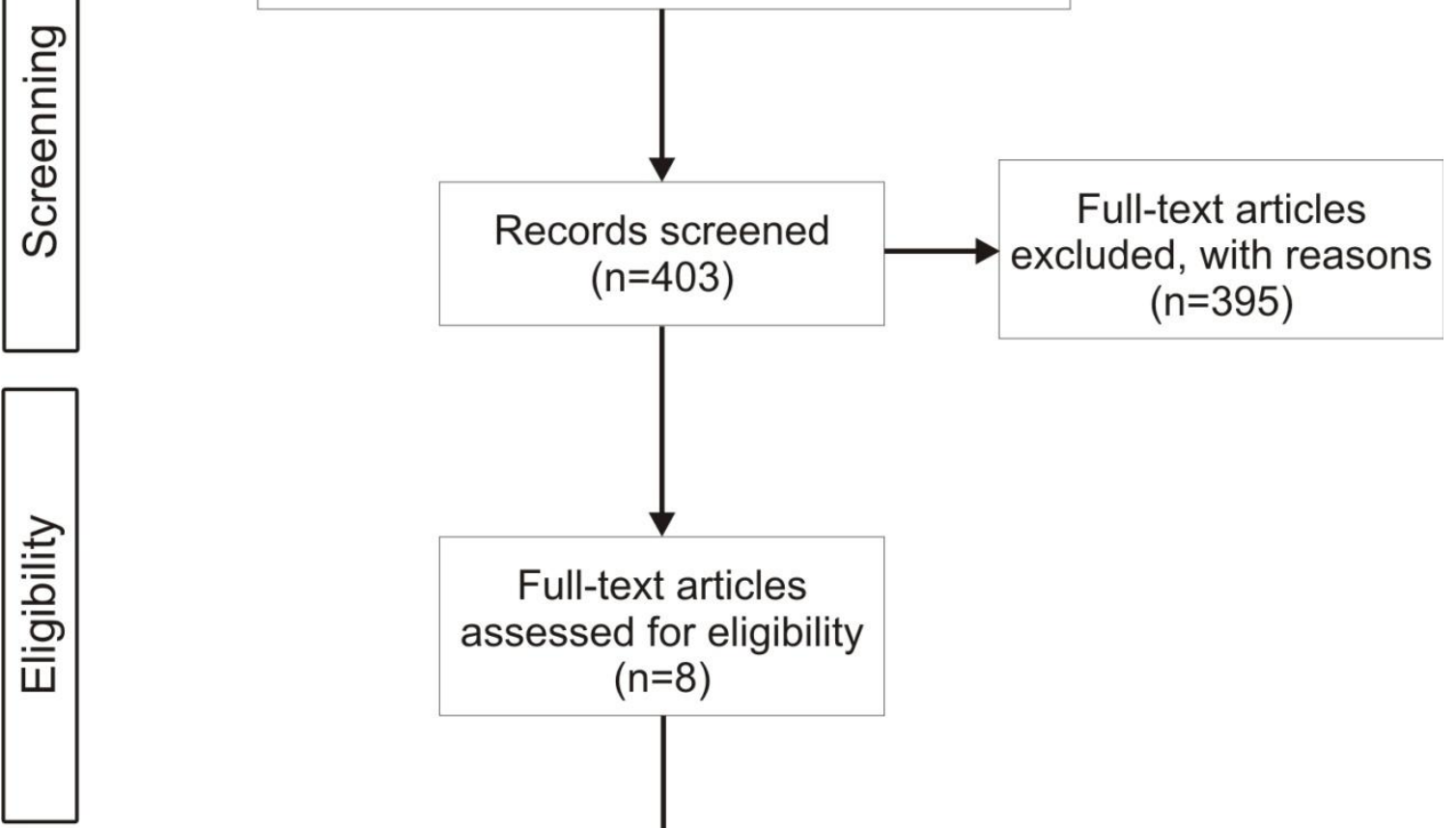

Full-text articles assessed for eligibility $(n=8)$

엄

Studies included in quantitative synthesis (meta-analysis) $(n=8)$ 


\section{Figure 3 (on next page)}

Mean effect on native diversity performance or survival across all trophic levels of nonnative vertebrates.

Fig 3 - In ecosystems invaded by two nonnative vertebrates, the removal of only a single invader had a negative mean effect on native diversity performance or survival (Hedges' $d+$ ) across all trophic levels. Error bars represent 95\% confidence intervals of the mean. 


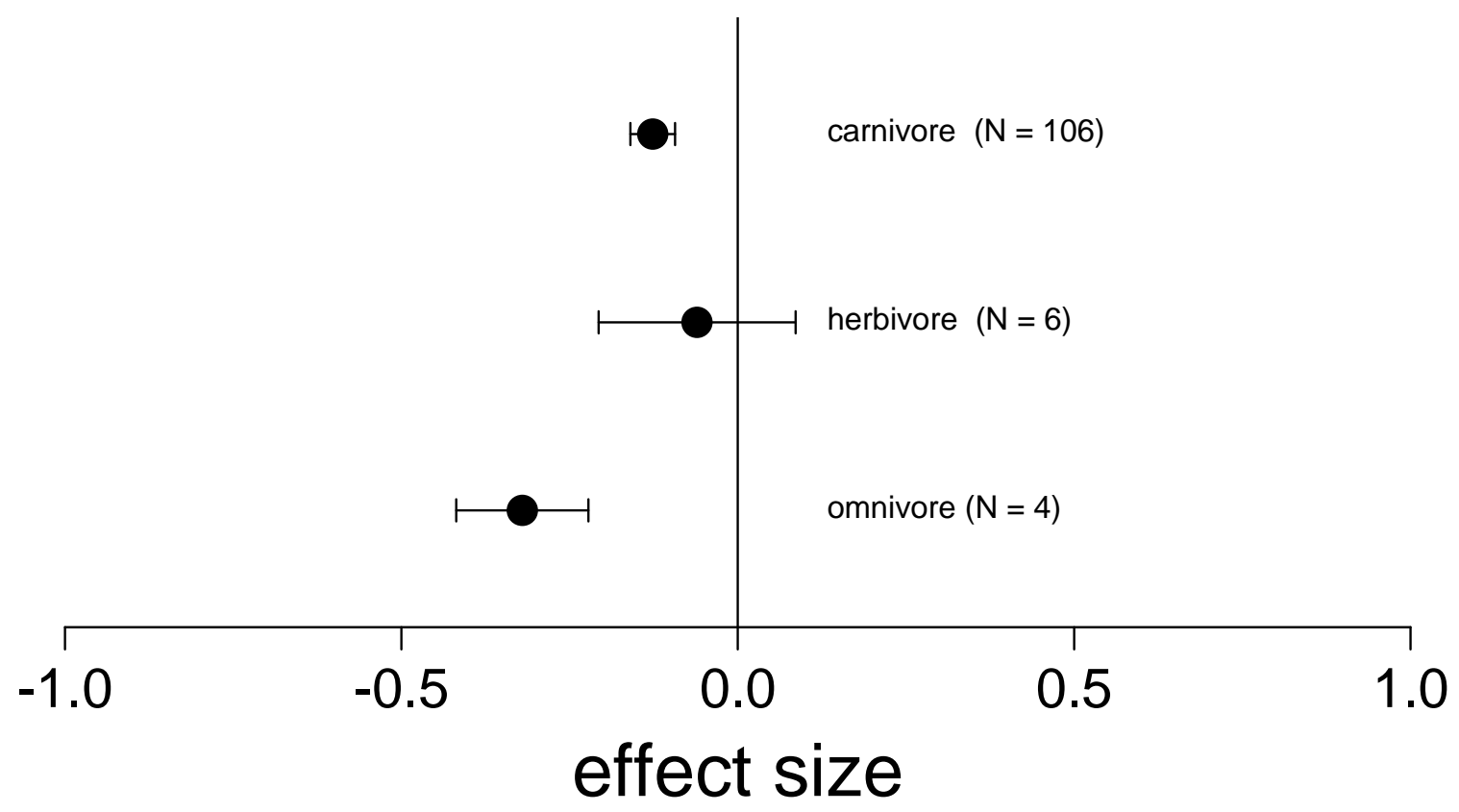




\section{Table 1 (on next page)}

List of references

Table 1. List of references used in this study for meta-analysis 


\begin{tabular}{|c|c|c|c|c|}
\hline $\mathbf{N}^{\circ}$ & Reference & Title & Journal & Location \\
\hline 1 & $\begin{array}{l}\text { Didham RK, Barker } \\
\text { GM, Costall JA, LH } \\
\text { Deanmean, Floyd CG, } \\
\text { Watts CH (2009) }\end{array}$ & $\begin{array}{l}\text { The interactive effects of livestock exclusion } \\
\text { and mammalian pest control on the } \\
\text { restoration of invertebrate communities in } \\
\text { small forest remnants }\end{array}$ & $\begin{array}{l}\text { New Zealand } \\
\text { Journal of Zoology }\end{array}$ & $\begin{array}{l}\text { Waikato } \\
\text { region, New } \\
\text { Zealand }\end{array}$ \\
\hline 2 & $\begin{array}{l}\text { Houde ALS, Wilson } \\
\text { CC, BD Neff (2014) }\end{array}$ & $\begin{array}{l}\text { Competitive interactions among multiple } \\
\text { invasive salmonids and two populations of } \\
\text { Atlantic salmon }\end{array}$ & $\begin{array}{l}\text { Ecology of } \\
\text { Freshwater Fish }\end{array}$ & $\begin{array}{l}\text { Ontario, } \\
\text { Canada }\end{array}$ \\
\hline 3 & $\begin{array}{l}\text { Latorre L, Larrinaga } \\
\text { AR, Santamaría L } \\
(2013)\end{array}$ & $\begin{array}{l}\text { Combined impact of multiple exotic } \\
\text { herbivores on different life stages of an } \\
\text { endangered plant endemism, Medicago } \\
\text { citrina. }\end{array}$ & Journal of Ecology & $\begin{array}{l}\text { Cabrera } \\
\text { Island, Spain }\end{array}$ \\
\hline 4 & $\begin{array}{l}\text { Oyugi DO, } \\
\text { Cucherousset J, } \\
\text { Britton JR (2012) }\end{array}$ & $\begin{array}{l}\text { Temperature-dependent feeding interactions } \\
\text { between two invasive fishes competing } \\
\text { through interference and exploitation }\end{array}$ & $\begin{array}{l}\text { Reviews in Fish } \\
\text { Biology and } \\
\text { Fisheries }\end{array}$ & $\begin{array}{l}\text { United } \\
\text { Kingdom }\end{array}$ \\
\hline 5 & $\begin{array}{l}\text { Porter-Whitaker AE, } \\
\text { Rehage JS, Liston SE, } \\
\text { Loftus WF (2012) }\end{array}$ & $\begin{array}{l}\text { Multiple predator effects and native prey } \\
\text { responses to two invasive Everglades } \\
\text { cichlids }\end{array}$ & $\begin{array}{l}\text { Ecology of } \\
\text { Freshwater Fish }\end{array}$ & $\begin{array}{l}\text { Everglades, } \\
\text { USA }\end{array}$ \\
\hline 6 & Smith KG (2005) & $\begin{array}{l}\text { Effects of invasive tadpoles on native } \\
\text { tadpoles in Florida: evidence of competition }\end{array}$ & $\begin{array}{l}\text { Biological } \\
\text { Conservation }\end{array}$ & Florida, USA \\
\hline 7 & $\begin{array}{l}\text { van Zwol JA, Neff BD, } \\
\text { Wilson CC (2012) }\end{array}$ & $\begin{array}{l}\text { The effect of invasive salmonids on social } \\
\text { dominance and growth of juvenile atlantic } \\
\text { salmon }\end{array}$ & $\begin{array}{l}\text { Transactions of the } \\
\text { American Fisheries } \\
\text { Society }\end{array}$ & $\begin{array}{l}\text { Ontario, } \\
\text { Canada }\end{array}$ \\
\hline 8 & $\begin{array}{l}\text { Wilson DJ, Ruscoe } \\
\text { WA, Burrows LE, } \\
\text { McElrea LM, } \\
\text { Choquenot D ( 2006) }\end{array}$ & $\begin{array}{l}\text { An experimental study of the impacts of } \\
\text { understorey forest vegetation and herbivory } \\
\text { by red deer and rodents on seedling } \\
\text { establishment and species composition in } \\
\text { Waitutu Forest, New Zealand }\end{array}$ & $\begin{array}{l}\text { New Zealand } \\
\text { Journal of Ecology }\end{array}$ & $\begin{array}{l}\text { Fiordland } \\
\text { National } \\
\text { Park, New } \\
\text { Zealand }\end{array}$ \\
\hline
\end{tabular}




\section{Table 2 (on next page)}

Meta-analysis

Table 2 - Results from a meta-analysis of 8 published manuscripts entailing 128 observations of invasive vertebrate interactions. We report the mean effect size and $95 \%$ confidence intervals (Hedge's $d+$ ) andbold values when the $95 \% \mathrm{Cl}$ does not overlap zero. Mean effect sizes were calculated for the entire data set and subsets of the data that compared the effect of mixed and single groups of invasive vertebrateson native biodiversity. 
1

\begin{tabular}{|c|c|c|c|}
\hline & $N$ & direction & Hedge's $d+$ \\
\hline \multicolumn{4}{|l|}{ HABITAT TYPE } \\
\hline forest & 16 & - & $-0.29 \pm 0.10$ \\
\hline wetland & 36 & - & $-0.13 \pm 0.05$ \\
\hline freshwater & 73 & - & $-0.11 \pm 0.05$ \\
\hline garrigue & 3 & - & $-0.16 \pm 0.15$ \\
\hline \multicolumn{4}{|l|}{ NATIVE RANGE OVERLAP } \\
\hline overlapping ranges & 46 & - & $-0.21 \pm 0.07$ \\
\hline non-overlapping ranges & 72 & - & $-0.13 \pm 0.03$ \\
\hline \multicolumn{4}{|c|}{ INVASIVE FUNCTIONAL GROUP } \\
\hline amphibian & 16 & 0 & $-0.13 \pm 0.13$ \\
\hline mammal & 19 & - & $-0.25 \pm 0.08$ \\
\hline fish & 93 & - & $-0.13 \pm 0.03$ \\
\hline \multicolumn{4}{|c|}{$\begin{array}{l}\text { TROPHIC POSITION OF REMOVED } \\
\text { INVADER }\end{array}$} \\
\hline carnivore & 106 & - & $-0.13 \pm 0.03$ \\
\hline $\begin{array}{l}\text { herbivore } \\
\text { omnivore }\end{array}$ & $\begin{array}{l}6 \\
4\end{array}$ & $\begin{array}{l}0 \\
-\end{array}$ & $\begin{array}{l}-0.06 \pm 0.15 \\
-\mathbf{0 . 3 2} \pm \mathbf{0 . 1 0}\end{array}$ \\
\hline
\end{tabular}

